\title{
Improvement in the Prediction of Ventilator Weaning Outcomes by an Artificial Neural Network in a Medical ICU
}

\author{
Hung-Ju Kuo MSc, Hung-Wen Chiu PhD, Chun-Nin Lee MD MSc, Tzu-Tao Chen MD, \\ Chih-Cheng Chang MD, and Mauo-Ying Bien PhD PT CRT
}

BACKGROUND: Twenty-five to $40 \%$ of patients pass a spontaneous breathing trial (SBT) but fail to wean from mechanical ventilation. There is no single appropriate and convenient predictor or method that can help clinicians to accurately predict weaning outcomes. This study designed an artificial neural network (ANN) model for predicting successful extubation in mechanically ventilated patients. METHODS: Ready-to-wean subjects $(N=121)$ hospitalized in medical ICUs were recruited and randomly divided into training $(n=76)$ and test $(n=45)$ sets. Eight variables consisting of age, reasons for intubation, duration of mechanical ventilation, Acute Physiology and Chronic Health Evaluation II score, mean inspiratory and expiratory times, mean breathing frequency, and mean expiratory tidal volume in a 30-min SBT (pressure support ventilation of $5 \mathrm{~cm} \mathrm{H}_{2} \mathrm{O}$ and PEEP of $5 \mathrm{~cm} \mathrm{H} \mathrm{H}_{2} \mathrm{O}$ ) were selected as the ANN input variables. The prediction performance of the ANN model was compared with the rapid shallow breathing index (RSBI), maximum inspiratory pressure, RSBI at $1 \mathrm{~min}\left(\mathrm{RSBI}_{1}\right)$ and $30 \mathrm{~min}\left(\mathrm{RSBI}_{30}\right)$ in an SBT, and absolute percentage change in RSBI from 1 to 30 min in an SBT $\left(\triangle \mathrm{RSBI}_{30}\right)$ using a confusion matrix and receiver operating characteristic curves. RESULTS: The area under the receiver operating characteristic curves in the test set of the ANN model was 0.83 (95\% CI $0.69-0.92, P<.001)$, which is better than any one of the following predictors: 0.66 (95\% CI 0.50-0.80, $P=.04)$ for RSBI, $0.52(95 \%$ CI $0.37-0.67, P=.86)$ for maximum inspiratory pressure, $0.53(95 \%$ CI $0.37-0.68, P=.79)$ for $\mathrm{RSBI}_{1}, 0.60(95 \%$ CI $0.44-0.74, P=.34)$ for $\mathrm{RSBI}_{30}$, and $0.51(95 \%$ CI $0.36-0.66, P=.91)$ for $\triangle \mathrm{RSBI}_{30}$. Predicting successful extubation based on the ANN model of the test set had a sensitivity of $82 \%$, a specificity of $73 \%$, and an accuracy rate of $80 \%$, with an optimal threshold of $\geq 0.5$ selected from the training set. CONCLUSIONS: The ANN model improved the accuracy of predicting successful extubation. By applying it clinically, clinicians can select the earliest appropriate weaning time. Key words: artificial neural network; weaning prediction; rapid shallow breathing index; spontaneous breathing trial; airway extubation; receiver operating characteristic curve. [Respir Care 2015;60(11):1560-1569. (C) 2015 Daedalus Enterprises]

\section{Introduction}

More than $39 \%$ of ICU patients require endotracheal intubation with ventilatory support. ${ }^{1}$ Choosing the appro-

\footnotetext{
Mr Kuo, and Drs Lee, Chen, and Chang are affiliated with the Division of Pulmonary Medicine, Department of Internal Medicine, Shuang Ho Hospital, New Taipei City, Taiwan. Mr Kuo and Dr Chiu are affiliated with the Graduate Institute of Biomedical Informatics, and Drs Lee and Bien are affiliated with the School of Respiratory Therapy, College of Medicine, Taipei Medical University, Taipei, Taiwan. Dr Bien is also affiliated with the Division of Pulmonary Medicine, Department of Internal Medicine, Taipei Medical University Hospital, Taipei, Taiwan.
}

This study was supported by grant 96TMU-WFH-16 from the Wan Fang Hospital, Taipei, Taiwan. The authors have disclosed no conflicts of interest. priate time for weaning a patient from mechanical ventilation and extubation is crucial for reducing the risks of prolonged ventilatory support and premature weaning. ${ }^{2-4}$ Various weaning predictors based on breathing pattern parameters have been used to assess weaning preparedness..$^{5-9}$ The rapid shallow breathing index (RSBI) ${ }^{3,10}$ and the out-

\footnotetext{
Mr Kuo presented a version of this paper at the AARC Congress 2012, held November 10-13, 2012, in New Orleans, Louisiana.

Correspondence: Mauo-Ying Bien PhD PT CRT, School of Respiratory Therapy, College of Medicine, Taipei Medical University, $250 \mathrm{Wu}$-Hsing Street, Taipei 11031, Taiwan. E-mail: mybien@tmu.edu.tw.
}

DOI: $10.4187 /$ respcare. 03648 
comes of a spontaneous breathing trial (SBT) with either a T-piece or low-level pressure support ventilation (PSV) ${ }^{11}$ are commonly used clinical methods. However, various thresholds and sensitivities of the RSBI exist among different patient populations and measurement conditions, ${ }^{12-14}$ and $25-40 \%$ of patients who pass an SBT develop failure signs after being weaned from mechanical ventilation. ${ }^{10,15,16}$ Weaning patients from ventilatory support is a complex issue. ${ }^{17}$ Until now, no single appropriate and convenient predictor or method could be used satisfactorily to help clinicians predict weaning outcomes. ${ }^{6,18}$

Medical decision-support systems based on an artificial neural network (ANN) have been developed in different medical areas. ${ }^{19}$ ANNs are computer-based algorithms that mimic the habits and structures of neurons. The most common application type of ANNs is a multilayer perceptron, which includes an input layer, an output layer, and at least one hidden layer. ${ }^{20}$ Each layer consists of several perceptrons (or neurons), and each perceptron between layers is connected by weights that are capable of autonomous adjustments and learning directly from experience during the training phases. The perceptrons then output an optimal result for solving nonlinear problems in the manner of the human brain. ${ }^{20,21}$ Because the training behavior of ANNs has yet to be satisfactorily explained, ANNs are often called black boxes. Therefore, sensitivity analysis or cross-validation has been used to explain how ANN models work. ${ }^{20}$ Gottschalk et al ${ }^{22}$ were the first to report that an ANN model that had been trained by using 4 variables (ie, tidal volume $\left[\mathrm{V}_{\mathrm{T}}\right]$, minute ventilation, breathing frequency, and maximum inspiratory pressure $\left[\mathrm{P}_{\mathrm{I}_{\max }}\right]$ ) recorded during an SBT in ICU subjects could be as effective as experts in predicting whether patients could be successfully weaned from mechanical ventilation. Mueller et $\mathrm{al}^{23}$ demonstrated that their ANN model outperformed clinical expertise and multiple logistic regression in predicting extubation outcomes in premature newborns. However, other studies presented poor results using ANN models to predict extubation outcomes in different respiratory care facilities. ${ }^{7}$ The main reasons for poor outcome prediction may be due to the differences in clinical input data and patient populations.

The purpose of this study was to develop a medical decision-support ANN model for clinicians in making extubation decisions. The model contains variables selected from a literature review with consideration for the convenience of data collection and involves subjects' characteristics and respiratory pattern parameters during SBTs. The optimal number of perceptrons in the hidden layer was determined by using cross-validation. The ability to predict successful extubation in ICU subjects with the final ANN model was compared with RSBI, $\mathrm{P}_{\mathrm{I}_{\max }}$, RSBI at $1 \mathrm{~min}\left(\mathrm{RSBI}_{1}\right)$ and $30 \mathrm{~min}\left(\mathrm{RSBI}_{30}\right)$ in an SBT, and absolute percentage change in RSBI from 1 to $30 \mathrm{~min}$ in an SBT $\left(\triangle \mathrm{RSBI}_{30}\right)$ by analyzing the receiver operating characteristic (ROC) curves.

\section{QUICK LOOK}

\section{Current knowledge}

Daily spontaneous breathing trials (SBTs) along with interruption of sedation is the current evidence-based standard of care for facilitating ventilator discontinuation. However, extubation failure remains between 10 and $20 \%$ in most trials. Methods to predict success remain an important research focus.

\section{What this paper contributes to our knowledge}

In a small group of subjects, an artificial neural network (ANN) developed based on subjects' characteristics and breathing pattern variables improved the accuracy of predicting successful extubation compared with the rapid shallow breathing index or maximum inspiratory pressure. The ANN used subjects' age, reasons for intubation, duration of mechanical ventilation, APACHE II scores, and breathing patterns during a 30-min SBT. The ANN had a sensitivity of $82 \%$, a specificity of $73 \%$, and an accuracy rate of $80 \%$.

\section{Methods}

\section{Study Population}

All protocols were approved by the institutional review board of the 2 hospitals that we investigated in Taipei, Taiwan, and written informed consent was obtained from the study subjects or their next of kin. A total of 136 intubated, mechanically ventilated, and ready-to-wean subjects ${ }^{3,10}$ hospitalized in a medical ICU over a 13-month period were included in this study. The subjects exhibited no acute pulmonary or neuromuscular problems or signs of increased intracranial pressure before the study, and their $\mathrm{S}_{\mathrm{pO}_{2}}$ was $\geq 95 \%$. In addition, subjects had to meet the following routine measurements of weaning profiles ${ }^{24-27}$ : bed position elevated to $30^{\circ}, \mathrm{P}_{\mathrm{I}_{\max }} \leq-18 \mathrm{~cm} \mathrm{H}_{2} \mathrm{O}$, spontaneous breathing frequency $\leq 38$ breaths/min, and RSBI $\leq$ 110 breaths $/ \mathrm{min} / \mathrm{L}$. All subjects were mechanically ventilated with a Evita 4 (Dräger, Lübeck, Germany) or Galileo Gold (Hamilton Medical, Reno, Nevada) ventilator in the PSV mode to maintain a $\mathrm{V}_{\mathrm{T}}$ of $\sim 10 \mathrm{~mL} / \mathrm{kg}$ of ideal body weight. Other ventilator settings were $\mathrm{F}_{\mathrm{IO}_{2}} \leq 0.4$, PEEP = $5 \mathrm{~cm} \mathrm{H}_{2} \mathrm{O}$, flow sensitivity setting $=2-3 \mathrm{~L} / \mathrm{min}$, and rise time $=0.1-0.2 \mathrm{~s}$. Sedatives, hypnotics, and narcotics were discontinued for at least $8 \mathrm{~h}$.

When the subject's primary physician made the extubation decision, an arterial blood gas or $\mathrm{S}_{\mathrm{pO}_{2}}$ was collected, and the ventilator mode was changed to $30 \mathrm{~min}$ of PSV at $5 \mathrm{~cm} \mathrm{H}_{2} \mathrm{O}$ with PEEP at $5 \mathrm{~cm} \mathrm{H}_{2} \mathrm{O}$ in an SBT 


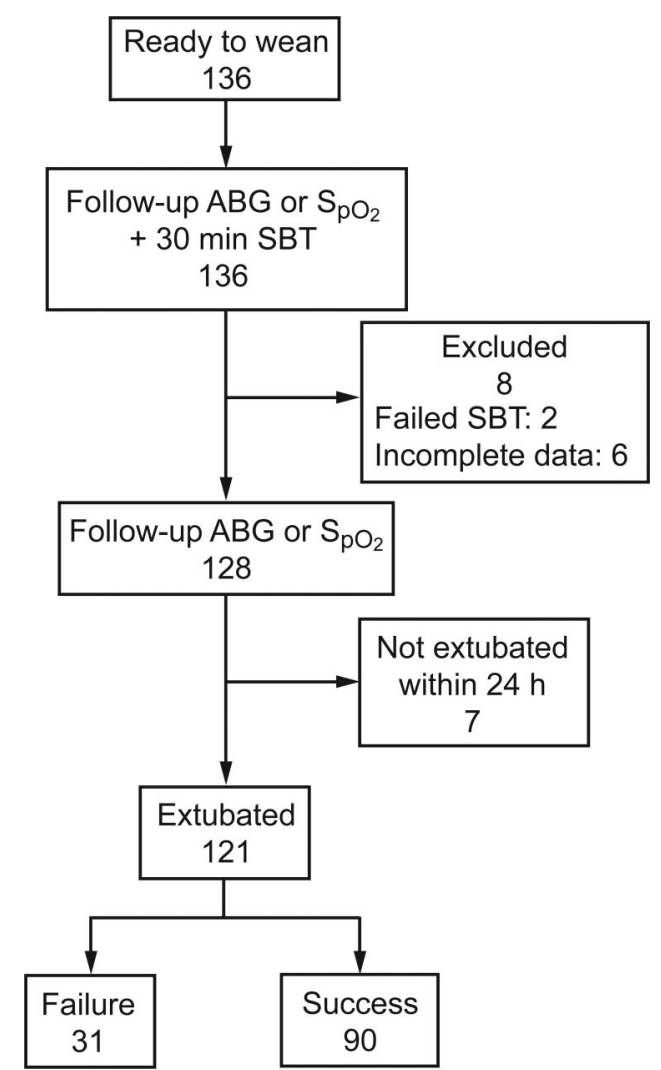

Fig. 1. Flow chart. Extubation failure was defined as re-intubation within $48 \mathrm{~h}$. SBT = spontaneous breathing trial; $\mathrm{ABG}=$ arterial blood gas test.

within $1 \mathrm{~h}$. A computerized pulmonary mechanics monitoring system $\left(\mathrm{CO}_{2} \mathrm{SMO}+\right.$ Model 8100 [Novametrix Medical Systems, Wallingford, Connecticut] or Ventilator Datalogger 3.27.1 [Hamilton Medical, Reno, Nevada]) was used to continuously record the flow, pressure, and volume signals during the trials. The trial was terminated, and the ventilator was returned to the previous level of pressure support if the subject had one or more signs of cardiopulmonary distress. ${ }^{3,10}$ When the subject passed the 30-min SBT, an arterial blood gas or $\mathrm{S}_{\mathrm{pO}_{2}}$ was collected, and the subject was then extubated and provided with a nasal cannula or airentrainment mask for oxygen therapy.

Fifteen subjects were excluded from the final analysis: 2 experienced respiratory failure during an SBT, 6 had incomplete data collection, and 7 were not extubated within $24 \mathrm{~h}$ after the SBT. Therefore, the data of 121 subjects were analyzed (Fig. 1). Extubation success was defined as a subject free from mechanical ventilation for $>48 \mathrm{~h}$ after extubation. If a subject exhibited one or more signs of cardiopulmonary distress within $48 \mathrm{~h}$ after extubation, ${ }^{10}$ the subject was reconnected to the ventilator with either noninvasive or invasive ventilation and was considered an extubation failure.

\section{Feature Selections}

Through the literature review, we found several potential parameters that can help clinicians predict the outcome of extubation. ${ }^{5,6,8,28,29}$ Cohen $^{30}$ observed the clinical data of subjects who had tolerated a 1-h SBT with CPAP at 5 $\mathrm{cm}_{2} \mathrm{O}$ and reported that the RSBI measured at the end of the SBT with automatic tube compensation was more sensitive than that measured without compensation. Furthermore, airway pressure and breathing frequency were also significantly different between the extubation failure and success groups at the end of the SBT. Frutos-Vivar et al ${ }^{15}$ collected clinical data from a multi-center study on subjects who had successfully passed an SBT and analyzed their data from the 24-h period before extubation, comparing the difference between the extubation and failure groups. They concluded that the RSBI, positive fluid balance $24 \mathrm{~h}$ before extubation, and diagnosis of pneumonia upon initiation of ventilation were most accurate in predicting extubation failure despite subjects completing the SBT.

Several physiological indexes have been developed to predict weaning outcome, such as RSBI, CROP (compliance, breathing frequency, oxygenation, and pressure) index, $P_{I_{\text {max }}}$, minute ventilation, ${ }^{25}$ and airway-occlusion pressure $0.1 \mathrm{~s}$ after the start of inspiration against an occluded airway. ${ }^{31}$ Meade $^{6}$ performed a meta-analysis to compare these physiological indexes in 65 observational studies by using a likelihood ratio, determining that the RSBI is one of the most powerful indexes of successful weaning. To improve the prediction of weaning outcomes, more physiological parameters may be considered. However, studies have shown that it is still controversial to use an arterial blood gas to facilitate elevating the accuracy rate of prediction after subjects have passed an SBT. 28,29

In breathing pattern-related research, Casaseca-de-laHiguera et $\mathrm{al}^{5}$ reported that breathing patterns during SBTs were more irregular in subjects who were eventually successfully extubated than subjects who failed extubation. The sample entropy of $V_{T}$ and the mean breathing frequency during SBTs can help clinicians determine whether patients can be successfully weaned from the ventilator. Other parameters of respiratory signals obtained during SBTs, such as frequency and $\mathrm{V}_{\mathrm{T}}$, can also facilitate achieving this purpose. ${ }^{32}$

After reviewing the potential parameters that may predict extubation outcomes, we considered the convenience of data collection for future application and discarded variables that were not available at the bedside at all times. Eight variables among 3 categories were selected for the input of the ANN: (1) demographic data (age and duration of mechanical ventilation), (2) physiological data (APACHE II [Acute Physiology and Chronic Health Evaluation II] score at the time of ICU admission and reasons for respiratory failure), and (3) breathing pattern obtained 
Table 1. Subjects' Physical and Clinical Characteristics

\begin{tabular}{|c|c|c|c|}
\hline Characteristic & Success $(n=90)$ & Failure $(n=31)$ & $P$ \\
\hline Age, mean $\pm \mathrm{SD}, \mathrm{y}^{*}$ & $74 \pm 15$ & $80 \pm 5$ & .19 \\
\hline Males/females, $n$ & $61 / 29$ & $23 / 8$ & .50 \\
\hline $\mathrm{BMI}$, mean $\pm \mathrm{SD}, \mathrm{kg} / \mathrm{m}^{2} \dagger$ & $21 \pm 5$ & $19 \pm 4$ & .01 \\
\hline APACHE II score on admission to the ICU, mean $\pm \mathrm{SD}^{*}$ & $21 \pm 7$ & $20 \pm 8$ & .91 \\
\hline Mechanical ventilation duration, mean $\pm \mathrm{SD}, \mathrm{d}^{* \dagger}$ & $12 \pm 17$ & $18 \pm 18$ & .01 \\
\hline \multicolumn{4}{|l|}{ Reasons for initiating mechanical ventilation, $n$} \\
\hline Acute COPD exacerbation & 13 & 7 & .30 \\
\hline Pneumonia & 49 & 15 & .56 \\
\hline Heart failure & 16 & 6 & .84 \\
\hline Neuromuscular disease & 6 & 5 & .11 \\
\hline Others $\dagger$ & 37 & 5 & .01 \\
\hline \multicolumn{4}{|l|}{ Past history, $n$} \\
\hline Respiratory disease & 46 & 22 & .05 \\
\hline Cardiovascular disease & 59 & 24 & .22 \\
\hline Neuromuscular disease & 27 & 4 & .06 \\
\hline \multicolumn{4}{|l|}{ Routine weaning profiles, mean $\pm \mathrm{SD}$} \\
\hline $\mathrm{P}_{\mathrm{I}_{\max }}, \mathrm{cm} \mathrm{H}_{2} \mathrm{O} \dagger$ & $-43 \pm 15$ & $-36 \pm 13$ & .04 \\
\hline Breathing frequency, breaths/min & $24 \pm 6$ & $26 \pm 5$ & .26 \\
\hline $\mathrm{V}_{\mathrm{T}}, \mathrm{mL}$ of ideal body weight $\dagger$ & $384 \pm 143$ & $317 \pm 67$ & .02 \\
\hline RSBI, breaths/min/L† & $72 \pm 31$ & $84 \pm 18$ & .02 \\
\hline \multicolumn{4}{|l|}{ Physiological data before weaning trials, mean $\pm \mathrm{SD}$} \\
\hline Systolic blood pressure, $\mathrm{mm} \mathrm{Hg}$ & $131 \pm 22$ & $130 \pm 23$ & .83 \\
\hline Diastolic blood pressure, $\mathrm{mm} \mathrm{Hg}$ & $65 \pm 16$ & $66 \pm 17$ & .79 \\
\hline Heart rate, beats/min $\dagger$ & $85 \pm 13$ & $96 \pm 17$ & $<.001$ \\
\hline $\mathrm{F}_{\mathrm{IO}_{2}}$ & $0.31 \pm 0.05$ & $0.31 \pm 0.04$ & .66 \\
\hline $\mathrm{S}_{\mathrm{pO}_{2}}, \%$ & $98 \pm 2$ & $97 \pm 2$ & .05 \\
\hline \multicolumn{4}{|l|}{ Breathing pattern parameters during SBT, mean \pm SD } \\
\hline Breathing frequency, breaths/min* $* \dagger$ & $22 \pm 6$ & $25 \pm 5$ & .01 \\
\hline $\mathrm{T}_{\mathrm{I}}, \mathrm{ms}^{* \dagger} \dagger$ & $1058 \pm 259$ & $922 \pm 169$ & .001 \\
\hline $\mathrm{T}_{\mathrm{E}}, \mathrm{ms}^{*} \dagger$ & $1886 \pm 663$ & $1612 \pm 495$ & .03 \\
\hline Expiratory $\mathrm{V}_{\mathrm{T}}, \mathrm{mL}^{* \dagger}$ & $385 \pm 115$ & $336 \pm 98$ & .03 \\
\hline Change in RSBI after $30 \mathrm{~min}, \%$ & $3.8 \pm 30.7$ & $6 \pm 24.6$ & .20 \\
\hline \multicolumn{4}{|l|}{ Physiological data after weaning trials, mean \pm SD } \\
\hline Systolic blood pressure, $\mathrm{mm} \mathrm{Hg}$ & $130 \pm 23$ & $132 \pm 22$ & .74 \\
\hline Diastolic blood pressure, $\mathrm{mm} \mathrm{Hg}$ & $66 \pm 16$ & $65 \pm 18$ & .64 \\
\hline Heart rate, beats/min & $86 \pm 13$ & $97 \pm 19$ & .01 \\
\hline $\mathrm{S}_{\mathrm{pO}_{2}}, \%$ & $98 \pm 1.8$ & $97.6 \pm 1.9$ & .20 \\
\hline RSBI after $30 \mathrm{~min}$, breaths/min/L $\dagger$ & $65 \pm 32$ & $86 \pm 33$ & .002 \\
\hline $\mathrm{ICU}$ stay, mean $\pm \mathrm{SD}, \mathrm{d} \dagger$ & $12 \pm 12$ & $20 \pm 14$ & $<.001$ \\
\hline Hospital stay, mean $\pm \mathrm{SD}, \mathrm{d} \dagger$ & $34 \pm 44$ & $47 \pm 39$ & .01 \\
\hline $\begin{array}{l}\text { Success refers to subjects who were successfully weaned from ventilators and } \\
\text { * Input variables of the artificial neural network in the study. } \\
\dagger P<.05 \text { was considered to be statistically significant. } \\
\text { BMI }=\text { body mass index } \\
\text { APACHE = Acute Physiology and Chronic Health Evaluation } \\
{ }_{\mathrm{I}_{\text {max }}=\text { maximum inspiratory pressure }} \\
\mathrm{V}_{\mathrm{T}}=\text { tidal volume } \\
\text { RSBI = rapid shallow breathing index } \\
\text { SBT }=\text { spontaneous breathing trial } \\
\mathrm{T}_{\mathrm{I}}=\text { inspiratory time } \\
\mathrm{T}_{\mathrm{E}}=\text { expiratory time }\end{array}$ & refers to subjects who $n$ & ected to a ventilator with & \\
\hline
\end{tabular}

during a 30-min SBT (mean frequency, mean inspiratory time, mean expiratory time, and mean expiratory $\mathrm{V}_{\mathrm{T}}$ ) ( Table 1). The reasons for respiratory failure were classified into 5 categories: COPD exacerbation, pneumonia, heart failure, neuromuscular diseases, and others.

\section{Structure of the ANN}

The ANN prediction model was designed using STATISTICA 8.0 (StatSoft, Tulsa, Oklahoma). The applied architecture was a multilayer perceptron combined 


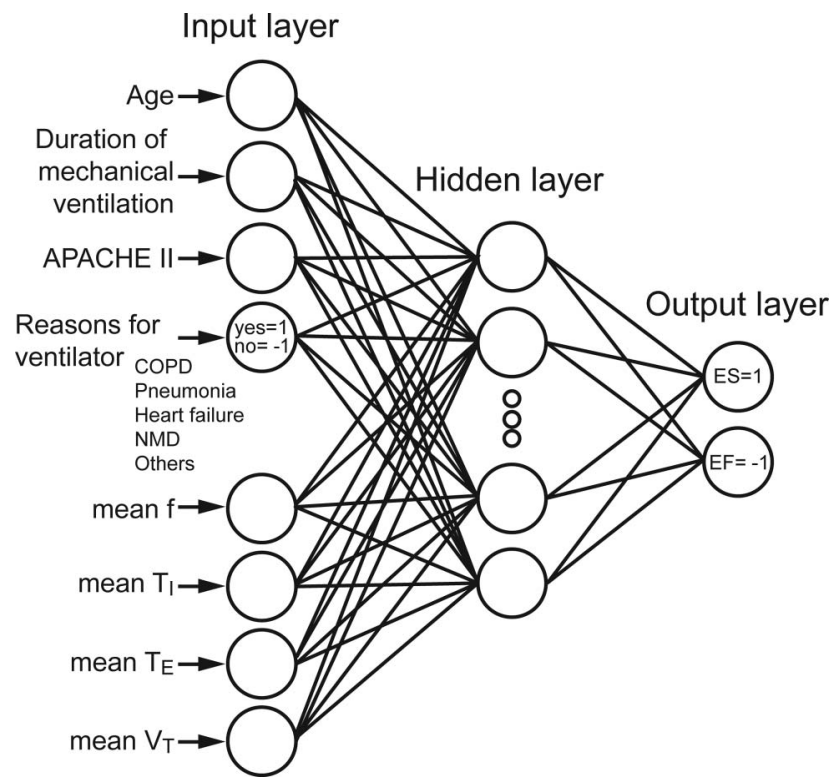

Fig. 2. An artificial neural network: a multilayer perceptron. The input layer included 8 variables; all of the perceptrons in the hidden and output layers had the same tangent sigmoid transfer function. APACHE II = Acute Physiology and Chronic Health Evaluation II; COPD = COPD exacerbation; NMD = neuromuscular diseases; $f=$ frequency; $T_{1}=$ inspiratory time; $T_{E}=$ expiratory time; $\mathrm{V}_{\mathrm{T}}=$ tidal volume; $\mathrm{ES}=$ extubation success; $\mathrm{EF}=$ extubation failure.

with a back-propagation algorithm. The designed ANN model consisted of an input layer containing 17 perceptrons defined according to the dummy variables of the abovementioned 8 input parameters. Two perceptrons in the output layer were used to export the prediction results. Because there was no standard method for determining a fixed perceptron number in the hidden layer, ${ }^{33}$ the number of perceptrons in the hidden layer was set empirically. To obtain an unbiased estimate of the generalization error and to determine the optimal number of perceptrons in the hidden layer, we used the leave-5-out-cross-validation (L5OCV) method. ${ }^{20}$ The L5OCV method generated 5 ANN models that had the same number of perceptrons in the hidden layer. For each model and its number of perceptrons in the hidden layer, the median of the area under the ROC curve was used to assess its performance. The model with the largest median of the area under the ROC curve was selected as the final ANN model. Figure 2 shows the architecture of the final ANN model designed in this study.

\section{Statistical Analysis}

The Kolmogorov-Smirnov or Shapiro-Wilk test was used to verify the normality of the data. The chi-square or Fisher exact test was used to analyze categorical variables, which were expressed as a frequency or a percentage. The con- tinuous variables were analyzed using a $t$ test or Wilcoxon 2 -sample test and expressed as the mean $\pm \mathrm{SD}$. The area under the ROC curve was used to compare the final ANN model with that of each RSBI, $\mathrm{P}_{\mathrm{I}_{\max }}, \mathrm{RSBI}_{1}, \mathrm{RSBI}_{30}$, and $\triangle \mathrm{RSBI}_{30}$ in predicting successful extubation. ${ }^{34}$ The optimal threshold value for each prediction model was established by analyzing the subjects in the training set, and all of the models were compared using only the test sets. Sensitivity represented subjects who had successful extubations and who had been predicted to be successful, whereas specificity stood for subjects who had unsuccessful extubations and who had been predicted to be unsuccessful. Diagnostic accuracy indicated the ability of the model to predict subject extubation outcome accurately. Data were analyzed using statistical software (SAS 9.4 [SAS Institute, Cary, North Carolina] and MedCalc 14.8 [MedCalc Software, Mariakerke, Belgium]), and $P<.05$ was considered to be statistically significant.

\section{Results}

\section{Subjects' Characteristics}

Table 1 presents the physical and clinical characteristics of all subjects studied $(N=121)$. The diagnosis for initiating mechanical ventilation of the study subjects included COPD exacerbations (16.5\%), pneumonia (52.9\%), heart failure $(18.2 \%)$, neuromuscular disease $(9.1 \%)$, and miscellaneous (eg, upper gastrointestinal bleeding and influenza, 34.7\%). All subjects passed a 30-min SBT, but 31 subjects exhibited signs of respiratory failure and had to be reconnected to mechanical ventilation within $48 \mathrm{~h}$ after extubation. Compared with the extubation success group $(n=90)$, subjects in the extubation failure group $(n=31)$ had significantly lower body mass indexes, longer duration of ventilatory support, longer ICU or hospital stays, and higher pulse rates. In addition, for initiating mechanical ventilation, fewer subjects in the extubation failure group were classified into the miscellaneous category. In the routine measurement of weaning profiles, $\mathrm{P}_{\mathrm{I}_{\max }}$, RSBI, and $\mathrm{RSBI}_{30}$ were significantly lower in the extubation success group, and $\mathrm{V}_{\mathrm{T}}$ was significantly lower in the extubation failure group. Regarding breathing pattern parameters during the SBT, subjects in the extubation failure group had significantly lower mean inspiratory times, mean expiratory times, and mean expiratory $\mathrm{V}_{\mathrm{T}}$ and faster mean breathing frequencies. Percentage change in the RSBI after the SBT yielded no significant difference.

\section{Weaning Prediction of the ANN Model}

All recruited subjects were randomly divided into a training set $(n=76)$ for training the final ANN model and a test set $(n=45)$ for validating the performance of the 
Table 2. Comparisons of the ANN Input Variables Between the Training and Test Sets

\begin{tabular}{lccc}
\hline \hline$\quad$ Variable & $\begin{array}{c}\text { Training Set } \\
(n=76)\end{array}$ & $\begin{array}{c}\text { Test Set } \\
(n=45)\end{array}$ & $P$ \\
\hline Age, mean $\pm \mathrm{SD}, \mathrm{y}$ & $77 \pm 11$ & $73 \pm 17$ & .52 \\
APACHE II score, mean $\pm \mathrm{SD}$ & $20 \pm 7$ & $22 \pm 8$ & .11 \\
COPD exacerbation, $n$ & & & \\
$\quad$ Yes & 11 & 9 & .43 \\
$\quad$ No & 65 & 36 & \\
Pneumonia, $n$ & & & \\
$\quad$ Yes & 40 & 24 & .94 \\
$\quad$ No & 36 & 21 & \\
Heart failure, $n$ & & & \\
$\quad$ Yes & 17 & 5 & .12 \\
$\quad$ No & 59 & 40 & \\
Neuromuscular disease, $n$ & & & \\
$\quad$ Yes & 5 & 6 & .21 \\
$\quad$ No & 71 & 39 & \\
Others, $n$ & & & \\
$\quad$ Yes & & & \\
$\quad$ No & & & \\
$\quad$ Duration of mechanical ventilation, \\
$\quad$ mean $\pm \mathrm{SD}, \mathrm{d}$
\end{tabular}

model. To prevent over-fitting during model training, a comparison between the training and test data sets regarding ANN variables was performed. As shown in Table 2, there was no significant difference between the training and test sets regarding the ANN input variables. To determine the optimal number of perceptrons in the hidden layer of the ANN prediction model, we developed a series of 5 cross-validated models and calculated the area under the ROC curves for both the training and test data sets based on the hidden-layer perceptron numbers, which ranged from 10 to 39 . The median of the area under the ROC curve represented the performance of each ANN model. The ANN model that contained 19 hidden perceptrons had the largest median of the area under the ROC curve (0.82) and was used as the final ANN model, which consisted of 17 perceptrons in the input layer, 19 percep- trons in the hidden layer, and 2 perceptrons in the output layer (multilayer perceptron 17-19-2) (Fig. 3).

The area under the ROC curves in the test set of the ANN model was 0.83 (95\% CI $0.69-0.92, P<.001)$, which is better than any one of the following predictors: 0.66 (95\% CI $0.50-0.80, P=.04$ ) for RSBI, 0.52 (95\% CI 0.37-0.67, $P=.86$ ) for $\mathrm{P}_{\mathrm{I}_{\max }}, 0.53(95 \%$ CI 0.37-0.68, $P=.79$ ) for $\mathrm{RSBI}_{1}, 0.60$ (95\% CI $0.44-0.74, P=.34$ ) for $\mathrm{RSBI}_{30}$, and $0.51(95 \% \mathrm{CI} 0.36-0.66, P=.91)$ for $\Delta \mathrm{RSBI}_{30}$ (Fig. 4). Predicting successful extubation based on the ANN model of the test set had a sensitivity of $82 \%$, a specificity of $73 \%$, and an accuracy rate of $80 \%$ with the optimal threshold of $\geq 0.5$ selected from the training set. The optimal threshold values selected from the ROC curves of the training set for RSBI, $\mathrm{P}_{\mathrm{I}_{\max }}, \mathrm{RSBI}_{1}, \mathrm{RSBI}_{30}$, and $\triangle \mathrm{RSBI}_{30}$ and their sensitivity, specificity, and diagnostic accuracy in predicting successful extubation from the test set are listed in Table 3.

\section{Discussion}

The challenges of minimally complicated measurement methods for weaning prediction have traditionally involved accuracy. Existing SBTs ${ }^{10,15,16}$ and weaning parameters, ${ }^{6,25,35,36}$ such as $V_{T}$, frequency, minute ventilation, $P_{I_{\max }}$, and RSBI, do not demonstrate a high degree of accuracy in predicting extubation outcomes. In this study, the ANN model was designed according to 8 input variables consisting of subjects' age, reasons for intubation, duration of mechanical ventilation, APACHE II scores, and breathing patterns obtained during a 30-min SBT. The proposed ANN model had better discrimination than existing predictors, such as RSBI, $\mathrm{P}_{\mathrm{I}_{\max }}, \mathrm{RSBI}_{1}, \mathrm{RSBI}_{30}$, and $\Delta \mathrm{RSBI}_{30}$, in predicting successful extubation.

The SBT has become a routine diagnostic test for determining whether patients can be successfully liberated from a ventilator, and patients' breathing patterns during SBTs have the potential to become weaning predictors. ${ }^{37,38}$ Because there is no difference in re-intubation or mortality rates for 30- and 120-min SBTs, ${ }^{39}$ we chose a $30-$ min SBT for data collection rather than a 120-min trial. Based on our literature review, breathing pattern parameters in an SBT have never been used as inputs of an ANN model. In comparing breathing pattern variables during an SBT with those of other studies, ${ }^{5,40}$ we observed that mean breathing frequency, mean inspiratory time, mean expiratory time, and mean $\mathrm{V}_{\mathrm{T}}$ showed statistically significant differences between the extubation success and failure groups, which indicated that the subjects developed a shallow breathing pattern during SBTs. Other studies have reported different results. ${ }^{9}$ The possible reasons for the difference may be attributed to the definition of extubation failure or the different level of pressure support during SBTs when collecting the breathing pattern parameters. Because of ethi- 


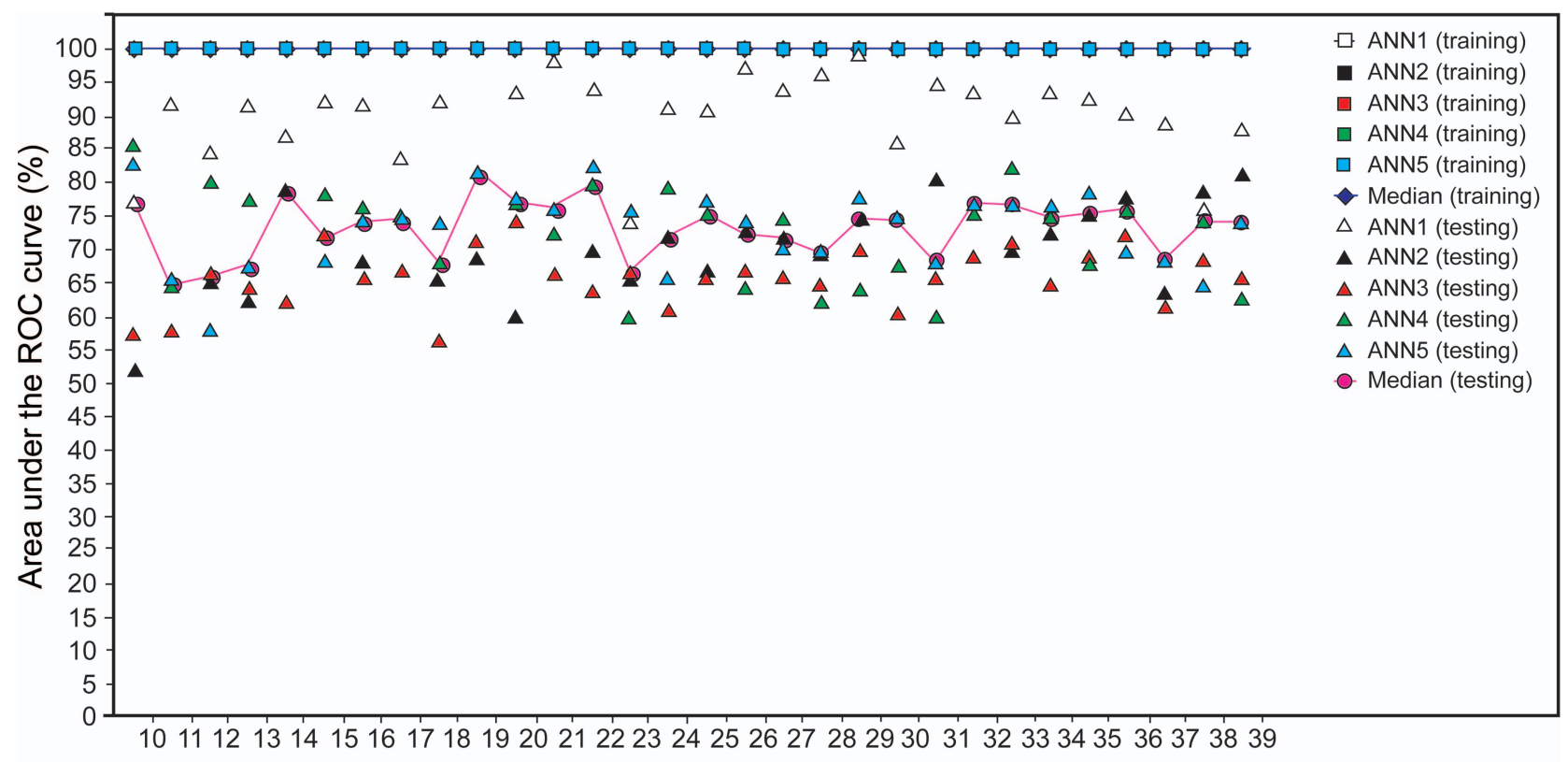

Neuron numbers of hidden layers

Fig. 3. Areas under the receiver operating characteristic $(\mathrm{ROC})$ curves for both the training and testing data sets based on a number of hidden-layer perceptrons from 10 to 39. The largest median area under the ROC curve of the test set represented the optimal number of perceptions in the hidden layer. With the neuron numbers set to 19 in the hidden layer, the area under the ROC curve became 0.82 . ANN $=$ artificial neural network.

cal concerns, the subjects in this study had to pass routine weaning profiles before the SBT and be extubated. This may have introduced a selection bias and affected the results when we compared the breathing pattern variables between the 2 groups.

Breathing patterns and their variability could also be influenced by different SBT methods. ${ }^{24}$ We collected subjects' breathing pattern parameters by conducting an SBT with a low level of pressure support, which could help specific medical ICU patients pass the SBT and also improve the success rate of extubation. ${ }^{41}$ Moreover, the efficiency and convenience of collecting data directly from a microprocessor ventilator met one of the criteria for an ideal weaning parameter. This facilitated designing a model by using the machine learning method, which may help clinicians to assess whether patients can be weaned from the ventilator quickly in a daily trial.

In this study, subjects in the extubation failure group all passed the routine weaning predictors, SBTs, and the primary physician's assessment. However, $25.6 \%$ of the subjects still experienced extubation failure. $\mathrm{P}_{\mathrm{I}_{\max }}, \mathrm{V}_{\mathrm{T}}$, and RSBI were found to be significantly different between the extubation failure and success groups. These results indicate that the threshold values of these routinely used predictors were not suitable for the subjects in this study. Therefore, their threshold values must be redefined. No significant difference was found in the percentage change in RSBI after a 30-min SBT, which was different from a previous study. ${ }^{42}$ The possible reasons for this difference may be attributed to different SBT methods used when collecting the breathing pattern parameters. Breathing pattern during SBTs under minimal ventilatory support (eg, CPAP or PSV) may reduce the predictive performance of breathing pattern variability. ${ }^{24,43}$

Although $\mathrm{P}_{\mathrm{I}_{\max }}, \mathrm{RSBI}, \mathrm{RSBI}_{1}, \mathrm{RSBI}_{30}$, and $\Delta \mathrm{RSBI}_{30}$ were not used as the input parameters for the ANN model, the prediction performance of the ANN model was more precise than any one of them. This result may indicate that more clinical parameters from the subject should be taken into consideration during an SBT before extubation. The ANN model can help clinicians make the final decision by learning from past experience like the human brain.

Previous studies reported that breathing pattern during SBTs may be a potential marker to predict weaning outcome. $^{5-9}$ The prediction accuracy rate and area under the ROC curve of the ANN model in this study were similar to those in other studies even when we took breathing pattern variables into consideration. 7,22 Different patient populations may have different key factors that determine who may be liberated from the mechanical ventilator. $\mathrm{Mu}-$ eller et $\mathrm{a}^{23}$ observed that gestational age, arterial blood gas, and ventilator settings were critical factors when deciding whether newborns could be successfully extubated. APACHE II, the Glasgow coma scale, RSBI, duration of mechanical ventilation, and other underlying diseases may 

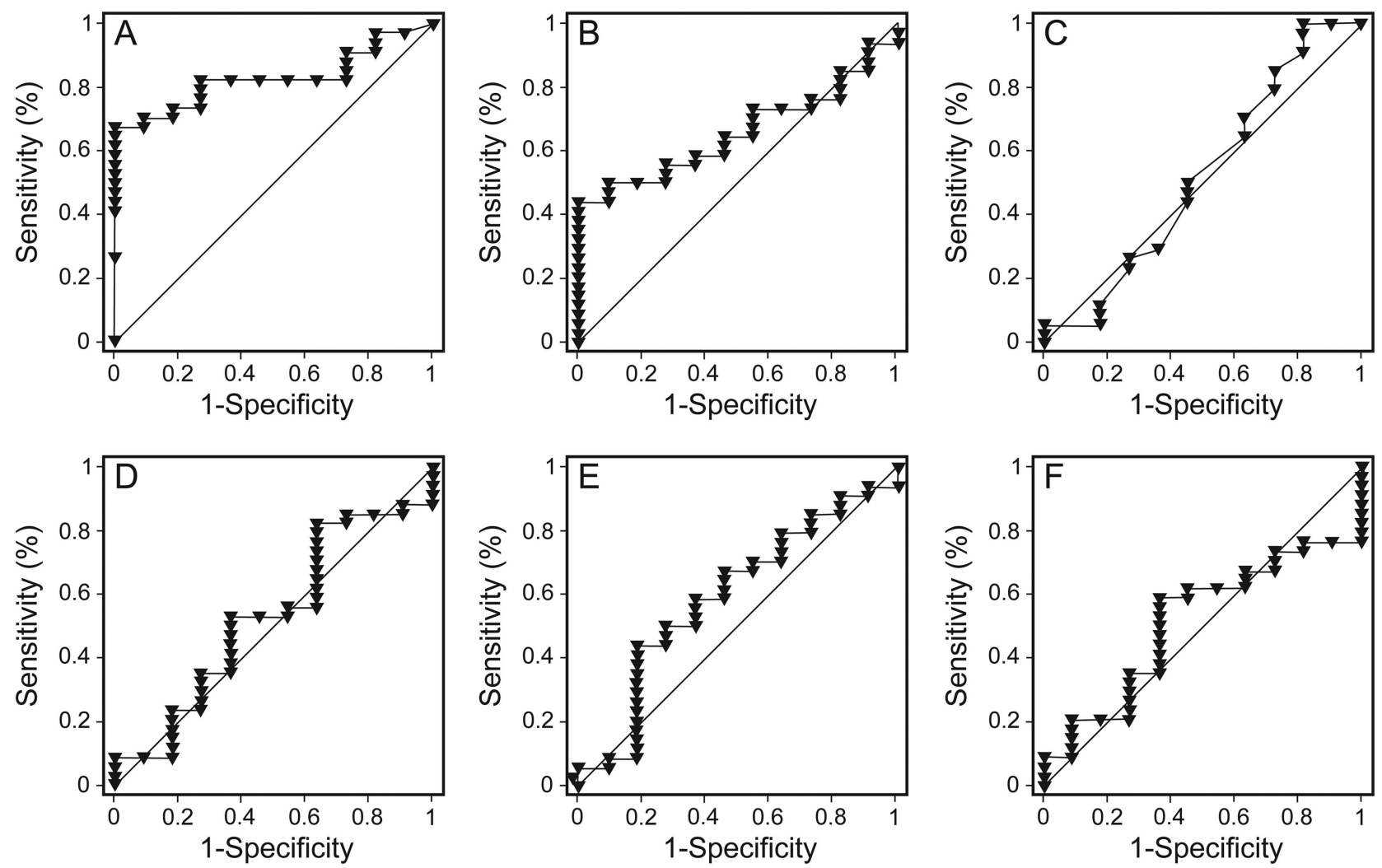

Fig. 4. Diagnostic performance of the artificial neural network (ANN) model (A), rapid shallow breathing index (RSBI) (B), maximum inspiratory pressure $\left(\mathrm{P}_{\mathrm{I}_{\max }}\right)(\mathrm{C}), \mathrm{RSBI}_{1}\left(\mathrm{RSBI}\right.$ at $1 \mathrm{~min}$ in an SBT) (D), $\mathrm{RSBI}_{30}\left(\mathrm{RSBI}\right.$ at 30 min in an SBT) (E), and $\Delta \mathrm{RSBI}_{30}($ absolute percentage change in RSBI from 1 to 30 min in an SBT) (F) in receiver operating characteristic (ROC) curve analyses. The areas under the ROC curves were $0.83(95 \% \mathrm{Cl} 0.69-0.92, P<.001)$ for the test set of the ANN model, $0.66(95 \% \mathrm{Cl} 0.50-0.80, P=.04)$ for $\mathrm{RSBI}, 0.52(95 \% \mathrm{Cl}$ $0.37-0.67, P=.86)$ for $\mathrm{P}_{\mathrm{I}_{\max }}, 0.53(95 \% \mathrm{Cl} 0.37-0.68, P=.79)$ for $\mathrm{RSBI}_{1}, 0.60(95 \% \mathrm{Cl} 0.44-0.74, P=.34)$ for $\mathrm{RSBI} 30$, and $0.51(95 \% \mathrm{Cl}$ $0.36-0.66, P=.91$ ) for $\Delta \mathrm{RSBI}_{30}$.

Table 3. Sensitivity, Specificity, and Diagnostic Accuracy for Predicting Successful Extubation in the ANN Model, RSBI, $\mathrm{P}_{\mathrm{I}_{\max }}, \mathrm{RSBI}_{1}, \mathrm{RSBI}_{30}$, and $\Delta \mathrm{RSBI}_{30}$ in the Test Set Using the Optimal Threshold Values From the Training Set

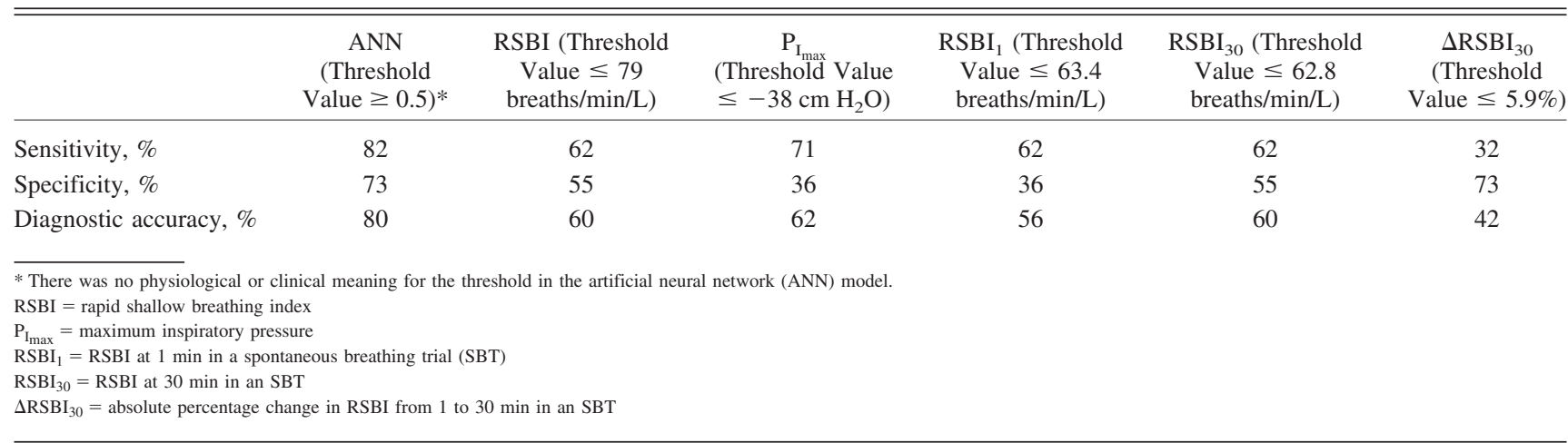

affect the success rate of extubation in patients who are ventilated for $>21 \mathrm{~d} .^{7}$ In this study, we applied 8 variables that were different from those mentioned previously. In addition, breathing patterns in the medical ICU were included as input variables of the ANN model. Based on these differences and the lack of a satisfactory explanation for the training behavior of the ANN model, comparison of the performance of the ANN model with that of previous studies is difficult.

This study has certain limitations. First, no subjects or key factors related to laryngeal edema after extubation were trained in the ANN model. Therefore, the ANN model 
may not be able to predict extubation failure caused by postextubation laryngeal edema. Second, selection bias could not be avoided because of ethical concerns, which may have caused an underestimation of the specificity in predicting the possibility of weaning failure of the ANN model. Finally, model-generated outcomes that do not provide explanations (eg, black box) constitute a major theoretical concern of the ANN model when applied to clinical studies. However, the success of ANNs in the medical decision-making system, such as high performance in predicting clozapine response ${ }^{44}$ and pain management, ${ }^{45}$ suggests that ANNs may be the solution to making complex decisions in clinical practice. Similar to a previous study, ${ }^{23}$ the L5OCV method was used in this study in an attempt to optimize the ANN model to prevent over-learning and obtain an unbiased estimate of the generalization error. We believe that our study is limited and do not know whether the proposed ANN model developed will perform similarly well in other institutions. However, because the ANN model can learn based on previous data, as a predictive model, it can be easily reconstructed in other institutions for local application by adopting the processes used in this study. When electronic medical records are fully implemented in the future, the proposed ANN model could become an efficient decision-support system.

\section{Conclusions}

The proposed ANN model, developed based on subjects' characteristics and breathing pattern variables, improved the accuracy of predicting successful extubation. By applying this ANN model clinically, clinicians can select the appropriate earliest weaning time, which could decrease the risks of unnecessarily prolonged ventilatory support and premature weaning. Therefore, the incidence of patients' complication rates and medical costs related to ventilatory support will decrease.

\section{ACKNOWLEDGMENTS}

We are grateful to Ms Chao-Yi Wu for help in preparing the manuscript.

\section{REFERENCES}

1. Esteban A, Anzueto A, Alía I, Gordo F, Apezteguía C, Pálizas F, et al. How is mechanical ventilation employed in the intensive care unit? An international utilization review. Am J Respir Crit Care Med 2000;161(5):1450-1458.

2. Epstein SK. Complications in ventilator supported patients. In: Tobin MJ, editor. Principles and practice of mechanical ventilation. New York, NY: McGraw-Hill, 2006;877-902.

3. MacIntyre NR, Cook DJ, Ely EW Jr, Epstein SK, Fink JB, Heffner $\mathrm{JE}$, et al. Evidence-based guidelines for weaning and discontinuing ventilatory support: a collective task force facilitated by the American College of Chest Physicians, the American Association for Respiratory Care, and the American College of Critical Care Medicine. Chest 2001;120(6 Suppl):375S-395S.
4. Seymour CW, Martinez A, Christie JD, Fuchs BD. The outcome of extubation failure in a community hospital intensive care unit: a cohort study. Crit Care 2004;8(5):R322-R327.

5. Casaseca-de-la-Higuera P, Martín-Fernández M, Alberola-López C. Weaning from mechanical ventilation: a retrospective analysis leading to a multimodal perspective. IEEE Trans Biomed Eng 2006; 53(7):1330-1345.

6. Meade M. Predicting success in weaning from mechanical ventilation. Chest 2001;120(6 Suppl):400S-424S.

7. Hsu J-C, Chen Y-F, Chen Y-H, Li C-H, Jiang X. Construction of prediction module for successful ventilator weaning. Lect Notes Comp Sci 2007;4570:766-775.

8. Giraldo B, Garde A, Arizmendi C, Jańe R, Benito S, Diaz I, Ballesteros D. Support vector machine classification applied on weaning trials patients. Conf Proc IEEE Eng Med Biol Soc 2006;1:55875590.

9. Arizmendi C, Romero E, Alquezar R, Caminal P, Díaz I, Benito S, Giraldo BF. Data mining of patients on weaning trials from mechanical ventilation using cluster analysis and neural networks. Conf Proc IEEE Eng Med Biol Soc 2009;2009:4343-4346.

10. Boles JM, Bion J, Connors A, Herridge M, Marsh B, Melot C, et al. Weaning from mechanical ventilation. Eur Respir J 2007;29(5): 10331056.

11. Girard TD, Ely EW. Protocol-driven ventilator weaning: reviewing the evidence. Clin Chest Med 2008;29(2):241-252.

12. El-Khatib MF, Jamaleddine GW, Khoury AR, Obeid MY. Effect of continuous positive airway pressure on the rapid shallow breathing index in patients following cardiac surgery. Chest 2002;121(2):475479.

13. El-Khatib MF, Zeineldine SM, Jamaleddine GW. Effect of pressure support ventilation and positive end expiratory pressure on the rapid shallow breathing index in intensive care unit patients. Intensive Care Med 2008;34(3):505-510.

14. Krieger BP, Isber J, Breitenbucher A, Throop G, Ershowsky P. Serial measurements of the rapid-shallow-breathing index as a predictor of weaning outcome in elderly medical patients. Chest 1997;112(4): 1029-1034.

15. Frutos-Vivar F, Ferguson ND, Esteban A, Epstein SK, Arabi Y, Apezteguía $\mathrm{C}$, et al. Risk factors for extubation failure in patients following a successful spontaneous breathing trial. Chest 2006;130(6): 1664-1671.

16. Epstein SK. Weaning from ventilatory support. Curr Opin Crit Care 2009; 15(1):36-43.

17. El-Khatib MF, Bou-Khalil P. Clinical review: liberation from mechanical ventilation. Crit Care 2008;12(4):221.

18. Sellarés J, Ferrer M, Torres A. Predictors of weaning after acute respiratory failure. Minerva Anestesiol 2012;78(9):1046-1053.

19. Lisboa PJ. A review of evidence of health benefit from artificial neural networks in medical intervention. Neural Netw 2002;15(1): 11-39.

20. Almeida JS. Predictive non-linear modeling of complex data by artificial neural networks. Curr Opin Biotechnol 2002;13(1):72-76.

21. Dayhoff JE, DeLeo JM. Artificial neural networks: opening the black box. Cancer 2001;91(8 Suppl):1615-1635.

22. Gottschalk A, Hyzer MC, Geer RT. A comparison of human and machine-based predictions of successful weaning from mechanical ventilation. Med Decis Making 2000;20(2):160-169.

23. Mueller M, Wagner CL, Annibale DJ, Hulsey TC, Knapp RG, Almeida JS. Predicting extubation outcome in preterm newborns: a comparison of neural networks with clinical expertise and statistical modeling. Pediatr Res 2004;56(1):11-18.

24. Bien MY, Shui Lin Y, Shih CH, Yang YL, Lin HW, Bai KJ, et al. Comparisons of predictive performance of breathing pattern variability measured during T-piece, automatic tube compensation, and 


\section{Artificial Neural Network for WeAning}

pressure support ventilation for weaning intensive care unit patients from mechanical ventilation. Crit Care Med 2011;39(10):2253-2262.

25. Yang KL, Tobin MJ. A prospective study of indexes predicting the outcome of trials of weaning from mechanical ventilation. $\mathrm{N}$ Engl J Med 1991;324(21):1445-1450.

26. Yang KL, Tobin MJ. Measurement of minute ventilation in ventilator-dependent patients: need for standardization. Crit Care Med 1991; 19(1):49-53.

27. Vitacca M, Paneroni M, Bianchi L, Clini E, Vianello A, Ceriana P, et al. Maximal inspiratory and expiratory pressure measurement in tracheotomised patients. Eur Respir J 2006;27(2):343-349.

28. Salam A, Smina M, Gada P, Tilluckdharry L, Upadya A, AmoatengAdjepong Y, et al. The effect of arterial blood gas values on extubation decisions. Respir Care 2003;48(11):1033-1037.

29. Pawson SR, DePriest JL. Are blood gases necessary in mechanically ventilated patients who have successfully completed a spontaneous breathing trial? Respir Care 2004;49(11):1316-1319.

30. Cohen JD. Automatic tube compensation-assisted respiratory rate to tidal volume ratio improves the prediction of weaning outcome. Chest 2002;122(3):980-984.

31. Sassoon CS, Mahutte CK. Airway occlusion pressure and breathing pattern as predictors of weaning outcome. Am Rev Respir Dis 1993; 148(4 Pt 1):860-866.

32. Nemer SN, Barbas CSV, Caldeira JB, Cárias TC, Santos RG, Almeida $\mathrm{LC}$, et al. A new integrative weaning index of discontinuation from mechanical ventilation. Crit Care 2009;13(5):R152.

33. Miller AS, Blott BH, Hames TK. Review of neural network applications in medical imaging and signal processing. Med Biol Eng Comput 1992;30(5):449-464.

34. DeLong ER, DeLong DM, Clarke-Pearson DL. Comparing the areas under two or more correlated receiver operating characteristic curves: a nonparametric approach. Biometrics 1988;44(3):837-845.

35. Nemer SN, Barbas CSV, Caldeira JB, Guimarães B, Azeredo LM, Gago R, Souza PC. Evaluation of maximal inspiratory pressure, tracheal airway occlusion pressure, and its ratio in the weaning outcome. J Crit Care 2009;24(3):441-446.

36. Conti G, Montini L, Pennisi MA, Cavaliere F, Arcangeli A, Bocci $\mathrm{MG}$, et al. A prospective, blinded evaluation of indexes proposed to predict weaning from mechanical ventilation. Intensive Care Med 2004;30(5):830-836

37. El-Khatib M, Jamaleddine G, Soubra R, Muallem M. Pattern of spontaneous breathing: potential marker for weaning outcome. Spontaneous breathing pattern and weaning from mechanical ventilation. Intensive Care Medicine 2001;27(1):52-58

38. Bien MY, Hseu SS, Yien HW, Kuo BI, Lin YT, Wang JH, Kou YR. Breathing pattern variability: a weaning predictor in postoperative patients recovering from systemic inflammatory response syndrome. Intensive Care Medicine 2004;30(2):241-247.

39. Esteban A, Alía I, Tobin MJ, Gil A, Gordo F, Vallverdú I, et al. Effect of spontaneous breathing trial duration on outcome of attempts to discontinue mechanical ventilation. Spanish Lung Failure Collaborative Group. Am J Respir Crit Care Med 1999;159(2):512518.

40. Giraldo BF, Chaparro J, Ballesteros D, Lopez-Rodriguez L, Geat D, Benito S, Caminal P. Study of the respiratory pattern variability in patients during weaning trials. Conf Proc IEEE Eng Med Biol Soc 2004;6:3909-3912.

41. Ezingeard E, Diconne E, Guyomarc'h S, Venet C, Page D, Gery P, et al. Weaning from mechanical ventilation with pressure support in patients failing a T-tube trial of spontaneous breathing. Intensive Care Medicine 2006;32(1):165-169.

42. Segal LN, Oei E, Oppenheimer BW, Goldring RM, Bustami RT, Ruggiero S, et al. Evolution of pattern of breathing during a spontaneous breathing trial predicts successful extubation. Intensive Care Med 2010;36(3):487-495.

43. Zhang B, Qin YZ. Comparison of pressure support ventilation and $\mathrm{T}$-piece in determining rapid shallow breathing index in spontaneous breathing trials. Am J Med Sci 2014;348(4):300-305.

44. Lin CC, Wang YC, Chen JY, Liou YJ, Bai YM, Lai IC, et al. Artificial neural network prediction of clozapine response with combined pharmacogenetic and clinical data. Comput Methods Programs Biomed 2008;91(2):91-99.

45. Pombo N, Araújo P, Viana J. Knowledge discovery in clinical decision support systems for pain management: A systematic review. Artif Intell Med 2014;60(1):1-11.

This article is approved for Continuing Respiratory Care Education credit. For information and to obtain your CRCE

(free to AARC members) visit www.rcjournal.com 